\title{
Strengthening the science-policy interface for climate adaptation: stakeholder perceptions in Cameroon
}

\author{
Elias Nkiaka ${ }^{1}$ (D) Jon C. Lovett ${ }^{1}$ \\ Received: 22 September 2017 / Accepted: 17 November 2018 / Published online: 11 January 2019 \\ (C) The Author(s) 2019
}

\begin{abstract}
Even when they are societally relevant, scientific research results do not always contribute to policy development for solving societal problems, with science and policy often on parallel lines failing to intersect. For scientific research to be useful for decision making, it must answer questions relevant for bridging the gap to policy, and so enhance the science-policy interface (SPI). In this study, Q methodology was used to capture perspectives from "multi-level" stakeholders holding different viewpoints about climate change in order to strengthen the SPI for climate adaptation in Cameroon. The views expressed by stakeholders resolved into three discourses which together explained 59\% of the Q-analysis variance. The first discourse explained $21 \%$ of the variance and focused on vulnerability and impacts of climate change. Under this discourse, stakeholders recognized the Sudano-Sahel and coastal zones as areas most vulnerable to climate change in Cameroon, with water resources and agriculture as the most vulnerable sectors. The second discourse explained $20 \%$ of the study variance and focused on adaptation planning. Political leadership was identified as crucially important for driving adaptation. The third discourse explained $18 \%$ of the study variance and centered on policy incentives. Key policy areas that can be put in place to raise the adaptive capacity of the population were identified. Proposed policies included integrated water resources management (IWRM) and the distribution of farm inputs to farmers to boost agricultural production. Under each discourse, stakeholders proposed a series of research areas that could be used as a starting point to strengthen the SPI initiative in Cameroon.
\end{abstract}

Keywords Science-policy interface $\cdot \mathrm{Q}$ methodology $\cdot$ Climate change adaptation $\cdot$ Stakeholders $\cdot$ Cameroon

\section{Introduction}

Adapting to a complex issue such as climate change is a multidimensional and dynamic process that requires informed decisions based on the potential impacts of climate change, public perceptions, knowledge, and experience (Iyalomhe et al. 2013) in order to understand the link between biophysical and social processes of change in a way that supports societal

Editor: Robbert Biesbroek

Electronic supplementary material The online version of this article (https://doi.org/10.1007/s10113-018-1441-4) contains supplementary material, which is available to authorized users.

Elias Nkiaka

E.Nkiaka@leeds.ac.uk

Jon C. Lovett

J.Lovett@leeds.ac.uk

1 School of Geography, University of Leeds, Leeds LS2 9JT, UK response to change (Weaver et al. 2014). Although higher level policy has emphasized the importance of adaptation (Conway 2011), lack of progress in delivering adaptation action may be attributed to the failure to connect climate science to societal needs (Moss et al. 2013).

An appropriate "science-policy interface" (SPI) approach is required to translate climate change scenarios into adaptation policies. However, uncertainty, complexity, diverse values, and the involvement of many sectors in climate modeling, together with linking the models to different policies with multiple objectives, make it difficult to communicate modeling results to non-specialists (Lovett 2015; Young et al. 2013). Therefore, there is "need to understand and analyse all of the interacting drivers and stressors, and identify policies and practices that can simultaneously address more than one issue at a time" (Watson $2005 \mathrm{p}$ 473). The aim of SPI is to bridge the gap between the scientific community and policy makers to enhance the use of scientific knowledge in decision making (Sarkki et al. 2014). The SPI framework does not occur in a vacuum; institutions and their configurations play key roles in 
contributing towards its implementation (Koetz et al. 2012), and different actors hold different views around complexity of climate change. For example, Conway and Mustelin (2014) have highlighted the role of institutions in the design, implementation, and coordination of multi-level and multi-sector activities to enhance climate adaptation.

Considering these uncertainties, complexities, and the high stakes involved in climate adaptation, different arguments have been made in favor of a participatory approach in the production of knowledge to facilitate decision making on issues related to climate adaptation. André and co-authors (André et al. 2012) and Wilsdon and Willis (2004) argue that knowledge co-produced through deliberative dialog with different stakeholders such as researchers, policy-makers, and local communities may be used to provide new perspectives and contextualize findings. Meanwhile, Few et al. (2007) articulated that stakeholder dialog could contribute to more effective adaptation to climate impacts by increasing the robustness of research results as well as the legitimacy of policies and measures. The importance of coupling climate impact research with policy to enhance adaptation in Africa has been highlighted (Conway 2011; Jones et al. 2015); but climate dynamics in the region are complex, making it difficult to distinguish between natural climate dynamics and humaninduced climate change.

Climate change affects different socio-economic sectors, so a wide range of institutions and actors are involved in the adaptation process; so to design scientific research that can enhance adaptation, a multi-sectoral approach is needed because climate change is a multi-sectoral challenge (Vincent and Colenbrander 2018). Furthermore, when considering the role stakeholders play in enhancing climate adaptation action, it is important to identify what the stakeholders consider as relevant scientific information that can be used to bridge the gap between science and policy. Scientific information on different aspects of climate change is being produced rapidly, but often does not contribute to policy development that can resolve societal problems, and so there appear to be two parallel lines that do not intersect (Lovett and Nkiaka 2017).

For scientific information to be useful for climate adaptation, it must answer important questions relevant for policy development, such as identifying the most vulnerable sectors, identifying the most vulnerable communities, how uncertainty is translated to risks for decision making and communicated to non-specialists, and how impacts in different sectors overlap, with a consideration that overlapping impacts can increase the risk of exposure (Piontek et al. 2014). Furthermore, application of scientific research for climate adaptation must also take into account multi-level governance involving organizations and institutions from both government and non-government actors on how to drive the adaptation agenda (Dujardin et al. 2017). This approach for addressing climate adaptation is a key knowledge gap in most countries of the Congo basin forest region, including Cameroon.
The objective of this study was to use Q methodology to capture the range of perspectives expressed by multi-level stakeholders holding different viewpoints about climate change in Cameroon. Stakeholder perspective is crucial for strengthening the science-policy interface because they can help researchers to identify the vulnerable regions/communities, the vulnerable sectors, and where to focus research efforts. Information generated from this study can also be used by donors and other actors to guide future climate adaptation actions in Cameroon, for example to mitigate against the "streetlight effect in climate change research in Africa" (Hendrix 2017 p 137). This effect is the tendency for researchers to focus on particular questions, cases, and variables for reasons of convenience or data availability, i.e., those visible under a scientific "street light," rather than broader relevance, policy import, or construct validity, i.e., those issues that are in the dark, outside the realms of standard scientific investigation. In contrast, the science-policy interface approach emphasizes that scientific research should be conducted according to relevance and policy uptake, and funding should be allocated following the same criteria.

\section{Methodology}

\section{Study area}

Cameroon is a democratic country in Central Africa situated in the Gulf of Guinea. The country has a total surface area of about $475,650 \mathrm{~km}^{2}$, with a population of about 20 million people and is classified as a low-middle-income country (Alemagi 2011; Water 2009). Monsoon circulation is the main source of rainfall with coastal areas receiving the highest amount where annual totals can reach $3850 \mathrm{~mm}$. Rainfall drops to between 600 and $1500 \mathrm{~mm}$ in the northern SudanoSahel part of the country (Nkiaka et al. 2017a). Agriculture is the mainstay of the country's economy, accounting for about $41 \%$ of gross domestic product (GDP) and employing more than $55 \%$ of the workforce (WRI 2007).

Temperatures are reported to have increased in Cameroon since the 1930s with a net increase of $0.95{ }^{\circ} \mathrm{C}$ between 1930 and 1999 (Ayonghe 2001). Although temperatures are projected to rise across the country due to climate change, there is no consensus among climate models on the projected mean annual rainfall in Cameroon; however, heavy precipitation events are expected to increase (Crawford et al. 2011). The country is considered vulnerable to the risk posed by climate change. For example, the Sudano-Sahel region of Cameroon has witnessed high climate variability during recent several decades (Nkiaka et al. 2017a; Nkiaka et al. 2017b). Furthermore, a recent assessment of CMIP5 models performance in the Lake Chad basin covering mostly the nothern regions of Cameroon indicated that future 
precipitation will increase slightly in the basin compared to the baseline period (Nkiaka et al. 2018). This may increase the risk of future flooding events and water-borne diesases in those areas. In addition, it has been reported that climate change and other stressors already limit freshwater availability and crop yields in many areas of Cameroon (Molua 2007; Yengoh 2012). The situation is expected to be exacerbated by additional stressors such as rapid land degradation, high population growth rate, poor economic growth and increasing social problems, spread of diseases, and a general degradation of ecosystems (Bele et al. 2011).

Notwithstanding, the country has earned the reputation of being a "laboratory" of institutional reforms in the Central African region (Atyi et al. 2013). This has been demonstrated recently by creation of the National Observatory for Climate Change (NOCC) by the Government of Cameroon. The main objective of the observatory is to bring together all government and non-government actors working in different aspects of climate change under one collaborative platform to promote the national science-policy interface for climate action. As a member state of the Congo basin, which contains the second largest rain forest in the world after the Amazon (Bele et al. 2011; Peach Brown 2011), several studies exploring different aspects of climate change have been carried out in Cameroon and other Congo basin countries. For example, Peach Brown (2011) investigated the role of gender as an effective strategy to foster participation in reducing emissions from deforestation and forest degradation (REDD+) programs; Somorin and co-authors (2012) looked at policy discourses on climate change adaptation and mitigation through the REDD+ mechanism in the Congo basin countries; Brown et al. (2014) studied the prospects of building institutional adaptive capacity in the Congo basin forests of Cameroon; Pavageau et al. (2018) examined the drivers of vulnerability of rural communities to climate variability in the Congo basin; and Nkiaka and Lovett (2018) focused on mainstreaming climate adaptation into sectoral policies in Cameroon. Most of these studies show that significant progress has been made in enhancing climate adaptation and mitigation in the forest sector in the Congo basin forest region. However, other potential vulnerable sectors such as agriculture, water resources, energy, and health remain largely under-studied; hence, the present study is needed to guide future research in some of these sectors.

\section{Identification of stakeholders}

To facilitate the identification of stakeholders in this study, a systemic inventory of potential stakeholders was carried out based on stakeholder role and other criteria such as function, knowledge, and hierarchical level as proposed by Ballejos and Montagna (2008). The function criterion refers to stakeholders who are formally responsible for climate change issues in Cameroon. These include government officials who prepare and implement policy, legal and regulatory decisions in the area of climate change. The institutions where these officials work include the Ministry of Environment, Sustainable Development and Protection of Nature (MINEPDED), Ministry of Energy and Water Resources (MINEE), Ministry of Agriculture and Rural Development (MINADER), and the Ministry of Forestry and Wildlife (MINFOF). The knowledge criterion refers to stakeholders who have relevant knowledge and skills related to climate change. They include technical ministries such as the Ministry of Scientific Research and Innovation (MINRESI), Ministry of Public Works, universities, research institutions, consultants, NGOs, and international organizations. The hierarchical criterion refers to influential stakeholders who can facilitate communication between stakeholders in both the public and private sectors. They include government ministers, heads of government research institutions, and heads of international organizations and NGOs. Table 1 gives a classification of stakeholders according to the roles and criteria outlined above.

\section{Implementation of Q methodology}

Developed by Stephenson (1953), Q methodology has become one of the most widely used methods for discourse analysis in social sciences especially in the context of development studies and has also been applied to scrutinize a wide range of environmental issues. For example, Frantzi and co-authors (Frantzi et al. 2009) applied the method to explore discourses on international environmental regime effectiveness; Albizua and Zografos (2014) applied Q methodology to elucidate a valuebased approach to vulnerability and adaptation to climate change; Lynch et al. (2014) also applied the method to study policy diffusion in water management in the Murray-Darling basin in Australia; Howard et al. (2016) used the method to explore the plural notions of fairness in Fairtrade Carbon Projects; and Dujardin and co-authors (Dujardin et al. 2017) used Q methodology to analyze viewpoints regarding climate change adaptation among key social actors from the field of development planning in the Philippines.

The popularity of Q methodology is due to the fact it offers the users both qualitative and quantitative research techniques. Quantitatively, it explores the "discourse" of the stakeholders concerning a particular theme under study through data collection and analysis using statistical and mathematical techniques; while qualitatively, it extracts qualitative, subjective data (information) from the participants about their views (Frantzi et al. 2009). In contrast to standard survey methods, the objective of $\mathrm{Q}$ methodology is not to establish patterns across individual characteristics such as age, gender, and class but instead, to look at patterns within and across individuals by focusing on their discursive understanding of a particular issue. One of the main advantages of this method is that statements used in the Q-sort are generated by the stakeholders 
Table 1 Classification of stakeholders according to role and criteria

\begin{tabular}{|c|c|c|c|}
\hline Stakeholder role & Stakeholder/organization & Definition & Criteria \\
\hline Supporters & IUCN & $\begin{array}{l}\text { Stakeholders who prepare and support adaptation } \\
\text { through advice and guidance and evaluation } \\
\text { of adaptation }\end{array}$ & Functional \\
\hline Providers & $\begin{array}{l}\text { Universities, Ministry of } \\
\text { Scientific Research and } \\
\text { Innovation, Consultants }\end{array}$ & $\begin{array}{l}\text { Stakeholders who provide research, knowledge, } \\
\text { and information on climate change causes, } \\
\text { impacts, vulnerabilities, and adaptation }\end{array}$ & Knowledge \\
\hline Disseminators & NGOs, Media & $\begin{array}{l}\text { Those who disseminate climate knowledge } \\
\text { and information }\end{array}$ & Knowledge \\
\hline Experts & $\begin{array}{l}\text { Ministry of Environment, } \\
\text { Sustainable Development } \\
\text { and Protection of Nature }\end{array}$ & $\begin{array}{l}\text { Local experts on climate systems, impacts of } \\
\text { climate change, and technical adaptation } \\
\text { solutions }\end{array}$ & Functional/knowledge/hierarchical \\
\hline $\begin{array}{l}\text { Responsible and/or } \\
\text { decision-makers }\end{array}$ & $\begin{array}{l}\text { Ministry of Environment, } \\
\text { Sustainable Development } \\
\text { and Protection of Nature }\end{array}$ & $\begin{array}{l}\text { Stakeholders that have an explicit responsibility } \\
\text { for climate policies, climate adaptation, or } \\
\text { activities hat are affected by climate change }\end{array}$ & Functional/hierarchical \\
\hline Regulators & $\begin{array}{l}\text { Ministry of Environment, } \\
\text { Sustainable Development } \\
\text { and Protection of Nature } \\
\text { and National Assembly } \\
\text { (not included in the study) }\end{array}$ & $\begin{array}{l}\text { Initiators of new legislation, as well as changes } \\
\text { in norms and standards }\end{array}$ & Functional/hierarchical \\
\hline
\end{tabular}

Table adapted from (André et al. 2012)

themselves during early stage of the research, and it allows these statements to be manipulated through ranking by the stakeholders so that the researcher has limited influence on the outcome of the results (Cuppen et al. 2010). Furthermore, it does not require a large population sample to produce statistically valid results (Frantzi et al. 2009). Implementation follows four distinct steps after identification of the theme to be investigated.

After identifying the stakeholders, the first step of Q methodology is to generate the concourse (set of statements) broadly representative of opinions surrounding a particular issue. This was achieved through semi-structured interviews. The questions were framed to cover broad themes related to climate change such as vulnerability and impacts; adaptation in climate sensitive sectors such as agriculture, water resources, energy, forestry, and health; factors that influence adaptation such as scientific research; government institutional structure; and challenges that impede climate adaptation. The first phase of the fieldwork was conducted in Yaoundé, Cameroon, from 2 November to 31 December 2015. Contacts were established between the researcher and the head of each of the identified ministries/institutions. The head of the institution then established links between the researcher and the different directors and staff responsible for climate change in that institution. Interviews were conducted in both English and French depending on the language of preference of the stakeholder, and the same questions were asked in both languages with each interview lasting for about $1 \mathrm{~h}$. The interviews were audio recorded with permission and were later transcribed and coded. During the first phase, an initial set of 165 statements was generated from 20 face-to-face interviews, complemented by information from relevant policy documents. All stakeholders interviewed were actively involved in climate change issues at different capacities in their respective ministries/institutions.

In the second step, the statements were reduced by filtering, while still conserving the diversity of viewpoints, claims, and ideas of the stakeholders who generated the statements (Cuppen et al. 2010). The statements were filtered to represent four sensitive sectors that are vital to the country's economy and the socio-economic wellbeing of the population (agriculture, water resources, energy, and forestry). The statements were further grouped under different themes such as vulnerability, impact, mitigation/adaptation, and institutional structures. The reason for using this approach was that it is easy for stakeholders to use the selected terms and themes as "search terms" to identify new scientific information published online by researchers working on climate-related issues in Cameroon and in the sub region. Using this approach, the statements were reduced to 36 to create the Q-sort. According to Van Exel and De Graaf (2005), the sample should normally be between 40 and 60 statements; however, Barry and Proops (1999) argue that a Q-sort of 36 statements is more easily manageable for both researchers and respondents.

The second phase of the fieldwork took place from 24 October to 23 December 2016. The Q-sort was given purposively to the stakeholders that were interviewed during the first phase of the study. In situations where the expert interviewed during the first phase was not available, the person was replaced by a colleague working in the same service at equivalent capacity. During the second phase of the fieldwork, the number of stakeholders increased for several reasons. Some stakeholders who declined to be interviewed during the first phase of the study were encouraged by their 
colleagues from other institutions because it was their first time to take part in a Q-sort, so they wanted their colleagues to experiment with something new as well. The number of stakeholders also increased because some stakeholders who were away in late 2015 because of the COP2 1 in France were back in their offices and decided to take part in the study.

The statements were prepared as a pack of cards and presented to stakeholders in both English and French depending on their language of preference. Each stakeholder was asked to read all the statements in the first instance, followed by separating the statements into two packs "agree" and "disagree." They were then asked to rank the statements according to individual perceived importance of each on a Likert scale from strongest agreement to strongest disagreement on a 9-column forced normal distribution grid. The reason for using a forced normal distribution is that it saves time later on when carrying out statistical analysis of results (Frantzi et al. 2009). The 27 participants who took part in this exercise were asked to rank the statements based on their personal viewpoints. Each stakeholder was asked open-ended follow-up questions after completing the Q-sorts to obtain additional information adopting the same approach used during the first phase of the study.

The Q-set was analyzed using the PQMethod software, version 2.35 because of the ease of entering the Q-sorts in the software. A $27 \times 27$ correlation matrix was produced from the Q-sort and subjected to factor analysis using the principal component analysis (PCA). The PCA was used to analyze the Q-sorts in this study instead of factor analysis because of the ease of implementing PCA in the PQMethod software. Moreover, acceptable results have been obtained from PCA technique in previous studies (Lynch et al. 2014; Dujardin et al. 2017). The PCA produces a number of factors, with each representing a group of respondents who share similar viewpoints in relation to the statements used in the study. The PCA analysis identified eight groups or discourses which were then rotated using the Varimax method to extract fewer but more meaningful discourses. The advantage of the Varimax rotation compared to other methods such as Promax is that it produces a simple solution such that each factor or discourse has a small number of large loadings and a large number of small loadings. This simplifies the interpretation of results as each original variable tends to be associated with a small number of factors, and each factor represents only a small number of variables (Abdi 2003).

Different criteria were used to determine the number of factors that comprise a discourse: (i) the Kaiser-Guttman criterion which states that a factor should have an eigenvalue $(E V)>1$; (ii) select only factors that have two or more sorts loading significantly on that factor alone (Watts and Stenner 2012). The significance is calculated using the expression $2.58(1 / \sqrt{ } N)$, where $N$ is the number of statements in the Qsort; (iii) the third criterion is the Humphrey's rule which states that a "factor is significant if the cross-product of its two highest loadings (ignoring the sign) exceeds twice the standard error" (Brown 1980). The standard error is calculated as $(1 / \sqrt{ } N)$, where $N$ is the number of statements.

\section{Results}

Three discourses were extracted following the Varimax rotation. A number of different outputs were compared before selecting the three-factor solution, which explained $59 \%$ of

Table 2 Participant loading for each factor

\begin{tabular}{llccc}
\hline Participant & Structure & Discourse & & \\
& & & & \\
& & $\mathrm{A}$ & $\mathrm{B}$ & $\mathrm{C}$ \\
P1 & Academia* & 0.5014 & 0.1933 & 0.5677 \\
P2 & Academia* & -0.0694 & 0.6011 & 0.6389 \\
P3 & Academia* & 0.5527 & 0.5302 & 0.1700 \\
P4 & COMIFAC** & 0.3673 & 0.4053 & 0.2148 \\
P5 & COMIFAC & $\mathbf{0 . 7 7 8 8 X}$ & 0.1791 & 0.2383 \\
P6 & CSO & 0.3874 & 0.1012 & $\mathbf{0 . 7 0 5 5}$ \\
P7 & CSO & $\mathbf{0 . 5 5 4 1 X}$ & 0.2906 & 0.3948 \\
P8 & CSO & 0.3893 & $\mathbf{0 . 5 6 2 2 X}$ & 0.2406 \\
P9 & CIFOR & 0.4285 & $\mathbf{0 . 6 2 0 6 X}$ & 0.173 \\
P10 & CIFOR & $\mathbf{0 . 6 6 1 7 X}$ & 0.0553 & 0.1609 \\
P11 & GIZ & 0.3201 & 0.413 & $\mathbf{0 . 5 6 2 6 X}$ \\
P12 & GIZ* & 0.499 & 0.6334 & 0.173 \\
P13 & IUCN* & 0.5005 & 0.6525 & 0.1122 \\
P14 & MINADER & $\mathbf{0 . 7 3 8 3 X}$ & 0.2323 & 0.3391 \\
P15 & MINADER & 0.1704 & 0.2936 & $\mathbf{0 . 7 0 5 5}$ \\
P16 & MINADER & 0.3896 & 0.3788 & $\mathbf{0 . 4 3 0 9 X}$ \\
P17 & MINEE & 0.1304 & 0.0749 & $\mathbf{0 . 6 2 5 6 X}$ \\
P18 & MINEE & 0.3528 & 0.2042 & $\mathbf{0 . 7 4 4 2 X}$ \\
P19 & MINFOF & $\mathbf{0 . 6 2 0 9 X}$ & 0.351 & 0.1573 \\
P20 & MINFOF** & 0.3129 & 0.1808 & 0.3524 \\
P21 & MINEPDED & $\mathbf{0 . 6 9 7 8 X}$ & 0.1961 & 0.4204 \\
P22 & MINEPDED & 0.0721 & $\mathbf{0 . 6 7 8 7 X}$ & 0.057 \\
P23 & MINEPDED & 0.1053 & $\mathbf{0 . 7 9 3 0 X}$ & 0.1579 \\
P24 & MINEPDED* & 0.5366 & 0.203 & 0.6454 \\
P25 & MINEPDED & 0.3516 & $\mathbf{0 . 5 0 1 6 X}$ & 0.3254 \\
P26 & MINEPDED & 0.3375 & $\mathbf{0 . 5 5 5 0 X}$ & 0.3506 \\
P27 & MINRESI & 0.042 & $\mathbf{0 . 6 7 4 5 X}$ & 0.4177 \\
& Eigen values & 5.67 & 5.40 & 4.86 \\
& \% study variance & 21 & 20 & 18 \\
& \% cumulative variance & 59 & & \\
\hline
\end{tabular}

* Confounder, ** non-significant sorts. Bold text with $\mathrm{X}$ indicates that the participant significantly loaded on this factor $(P<0.01)$

Significant loading sorts

Discourse A: (6) 5,7,10,14,19,21

Discourse B: (7) 8, 9, 22, 23, 25, 26, 27

Discourse C: (6) 6,11,15, 16, 17, 18

Confounders: (6) 1, 2, 3, 12, 13, 24

Non-significant sorts: (2) 4, 20

MINEPDED, Ministry of Environment, Sustainable Development and Protection of Nature; MINEE, Ministry of Energy and Water Resources; MINADER, Ministry of Agriculture and Rural Development; MINFOF, Ministry of Forestry and Wildlife; COMIFAC, "Commission des Forêts d'Afrique Centrale"; $C S O$, Civil Society Organization (environmental); CIFOR, Centre for International Forestry Research; GIZ, German Technical Cooperation; IUCN, International Union for Conservation of Nature 
the study variance. Study variance above $35 \%$ is ordinarily considered to be a sound solution in factor analysis (Kline 2014). The study variance obtained in this study is high compared to previous studies (Frantzi et al. 2009; Davies et al. 2016; Howard et al. 2016). This high variance can be attributed to the fact that most of the participants were able to identify positively with viewpoints expressed in each of the discourses. The statement scores for each discourse (factor array) are available in the online Supplementary Table.

Using this approach, discourse A had six significant loaders, discourse B had seven significant loaders, and discourse $\mathrm{C}$ had six significant loaders. Six confounders and two non-significant loaders were identified. Confounders are Q-sorts that loaded significantly on more than one factor while non-significant loaders are Q-sorts that did not load significantly on any factor (Table 2).

\section{Discourse A: vulnerability and impacts}

Discourse A explained $21 \%$ of the study variance and focused mainly on vulnerability and impacts of climate change to the society and had significant loaders from across various institutions representing different interest groups and viewpoints. The discourse strongly agrees with the following statements: Water resources are vulnerable to climate change so they have to be managed in a more sustainable and efficient way (No 6, $+4)$. All ecological zones in Cameroon are vulnerable to climate change, although the Sudano-Sahel and coastal zones remain the most vulnerable (No $32,+3)$. The government should put in place an insurance scheme to compensate victims of climate-induced disasters (No 27, +3 ). Land grabbing from local communities by multi-national companies increases their vulnerability to climate change and compromises the opportunities offered by carbon credits from forest conservation (No 29, +2). Lack of basic infrastructure in rural areas (e.g., pipe-borne water, farm-to-market roads, and hospitals) increases the vulnerability of the rural population to climate change (No $25,+1)$.

However, this discourse disagrees with the following statements: Sufficient technological skills, infrastructure, and consistent observational records needed for impact studies to enhance policy development are available to climate scientists in Cameroon (No 34, -4). Uncertainty about risks and the impacts of climate change should be an excuse for inaction by the government (No 21, -4). Discourse A also disagrees with the statement that food security in Cameroon will not be threatened by climate change (No, 13, -2) and that impact studies do not offer any opportunities for local adaptation (No $5,-1$ ).

The vulnerability and impacts of climate change across different regions and sectors were raised by the stakeholders. Stakeholders identified water resources to be particularly vulnerable to climate change because of rainfall vagaries, and this is perceived as a major threat to food insecurity in the country.
Many stakeholders under this discourse also agree with the concept of an insurance scheme that could be put in place by the government to compensate victims of climate-induced catastrophes. Generally, climate change has been identified as a major cause of disasters in Cameroon with significant socioeconomic ramifications especially for rural communities (Gaston et al. 2012; Ndille and Belle 2014).

Furthermore, the lack of basic infrastructure was also identified as a factor that increases vulnerability to climate change. During post Q-sort interviews, many stakeholders (mostly government officials) were of the opinion that absence of investment for infrastructure development was a major impediment to climate adaptation. The role of scientific research in enhancing adaptation to climate change through impact studies was well recognized by stakeholders. However, they lamented the lack of state-of-the-art technological infrastructure, absence of qualified personnel, and regarded insufficient observational records as a major impediment for carrying out climate impact research. According to them, these are some of the factors that compromise the possibility of reducing uncertainty about risks and impacts of climate change. During post Q-sort interviews, some stakeholders (mostly in the Ministries of Forestry and Environment working under REDD + pilot projects) remarked that land grabbing was a serious issue that could significantly increase the vulnerability of some forestdependent communities. Some stakeholders proposed that scientific research areas under this discourse could include among others investigating the impacts of climate change on water resources in the Sudano-Sahel region of Cameroon, impact of climate change on crop productivity for both staples and cash crops, and how to communicate uncertainty from climate model output to non-specialist audience.

Under this discourse, stakeholders presented a succinct description of the sectors and regions/areas most vulnerable to climate change in Cameroon, with the SudanoSahel region considered to be the most vulnerable owing to past climate variability. Furthermore, stakeholders recognize that climate change will increase the vulnerability of water resources and agriculture sectors, which could lead to food insecurity in Cameroon. In addition, secondary factors that act together to increase the vulnerability of the local population were also identified, such as the lack of basic infrastructure, absence of qualified scientists, lack of observational datasets and technological development for conducting scientific research to reduce vulnerability, and land grabbing from forest dependent communities.

\section{Discourse B: adaptation planning}

This discourse explained $20 \%$ of the study variance and was concerned with climate change adaptation planning at the national level to ensure climate resilient development given that the most severe impacts of climate change will become 
apparent only in the future. The discourse strongly agrees with the following statements: Climate change adaptation must take into account the complexity of societal processes and actors $($ No $1,+4)$. Therefore, developing adaptation policies using the multi-sectoral approach and mainstreaming adaptation into existing policies present better options for adaptation than sectoral approaches (No 31, +4; No 9, +2). Climate change adaptation planning will receive additional impetus if it is backed by a strong political leadership together with key government ministries responsible for finance and development planning (No 19, +3). Furthermore, climate change adaptation will be enhanced if scientists can translate the uncertainty inherent in climate models output into risk relevant for planning and decision making (No $4,+3$ ). To enhance decision making, climate and weather forecast information (climate services) should answer practical questions such as changes to the onset of the rainy season, frequency and duration of dry spells early in the growing season, water availability for irrigation, and intensity of extreme weather events (No $35,+3)$. Some REDD+ projects at local level fail not because the local communities are left out during project inception and execution but due to the lack of transparency in project management $($ No $7,+2)$. In the area of energy, developing hydroelectric dams across the country will significantly reduce Cameroon's carbon footprint (No 11, +2). Government should invest in public transportation systems in urban areas and setup an agency to monitor carbon use efficiency of imported cars (No 14, +1 ) to further reduce the country's carbon footprint.

Disagreement statements included are as follows: Solving immediate development challenges is more important than climate change which is an issue for future generations (No 3,-3) and diversification of livelihood activities will not enhance the adaptive capacities of the local population (No 26, -2).

During post Q-sort discussion, most stakeholders emphasized the importance of political leadership in driving the adaptation agenda in Cameroon. This has been demonstrated in other African countries such as Rwanda (Byamukama et al. 2011). Stakeholders in the Ministry of Agriculture recognized that farmers need weather information to plan their farming activities. This information could include rainy season onset and duration of dry spells in the rainy season, which can be provided in the form of climate services to help them plan for their farming operations such as field preparation, planting dates, and when to purchase farm inputs. However, they stated that the acquisition of climate services is expensive and out of reach of most farmers, so the government has to provide them with this information especially before the beginning of the farming season and throughout the rainy season. The need for climate services to help farmers adapt was corroborated by two different stakeholders working with international organizations. They suggested that Cameroon could join existing climate services networks in the region such as the Famine
Early Warning System (FEWs). Stakeholders were all unanimous that such information could be sent to the farmers through short telephone messages (SMS) or broadcasted through community radios.

During post Q-sort discussions, one of the stakeholders working for an international NGO expressed the opinion that some REDD+ projects have failed to create a positive impact on the livelihood of the beneficiary population because of the lack of transparency in project budget management. The stakeholders emphasized the need for such projects to recruit adequately trained technical and financial personnel to ensure that projects are executed following the terms of reference and also to ensure financial transparency in the management of funds. Nevertheless, other studies have shown that most climate adaptation finances to developing countries are channeled as development aid, with many bottlenecks in the management of funds, thereby limiting control by target countries over those funds (Scoville-Simonds 2016). However, results from this study show that governance, management, and accountability over climate adaptation funds remain an important issue that has to be tackled to ensure accountability.

Stakeholders went further to suggest that scientific research to enhance policy development under this discourse could target areas such as identifying user needs and uptake for weather and climate services in Cameroon, investigating impacts of REDD+ projects on the livelihood of selected villages in Cameroon, and investigating livelihood-coping strategies for agrarian population in selected regions.

\section{Discourse C: policy incentives}

Discourse C explained 18\% of the study variance and focuses mostly on policy incentives that need to be put in place to enhance adaptation. Discourse $\mathrm{C}$ strongly agrees that government should provide incentives for renewable energy use across the country, for example by reducing custom duties on the importation of renewable energy installation equipment and by implementing policies that reduce energy wastage in public buildings and encourage waste recycling (No 33, +4; No $12,+3)$. This discourse is also in favor of managing water resources in a more sustainable and efficient way (No $6,+4)$ as they are vulnerable to climate change. In addition, developing water-harvesting and storage infrastructure will enhance adaptive capacity of the local population in drought-prone areas (No 30,+3). This discourse also supports the fact most adaptation projects at local level fail because the beneficiary population is not consulted prior to project conception and execution (No 16, +3). Policy makers and the climate science community need to engage in a more interactive dialog so that both producers and users of scientific information can clearly state their needs $($ No $18,+2$ ). Forest conservation and management represents an effective way to mitigate climate 
change and reduce the vulnerability of water resources (No $15,+2)$.

However, Discourse C disagrees with the statements that an impediment to policy development is the noncommunication of impact studies results to decision makers and that the latter do not offer any opportunities for local adaptation (No 2, -1 ; No 5, - 3). Other statements that this discourse does not agree with are as follows: even if women have access to land for agriculture, this may not increase their adaptive capacity because they lack basic farm inputs (No 17, -1) and that there is no need to include climate change education in academic programs because the media will educate everybody (No 28, -4).

During post Q-sort discussion, most government stakeholders in the Ministry of Environment opined that the reduction of custom duties could go a long way to increase the importation of renewable energy equipment. They argued that such an initiative will help reduce prices and this will encourage the use of such equipment by the population. This was corroborated by a stakeholder in the Ministry of Energy and Water Resources who articulated that such an initiative will reduce the dependence of households and industries on the national grid and could boost industrial production, especially during the dry season. In fact, it has been observed in Cameroon that during the dry season, there are frequent power cuts or load-shedding due to a substantial drop in water level in the main reservoir used for hydro-power generation resulting significant economic losses to industries (Diboma and Tatietse 2013). However, one stakeholder cautioned that the implementation of such a policy remains solely a government responsibility because reducing customs duties may result in a drop in state revenue.

Stakeholders in the Ministry of Energy and Water Resources stated that due to the vulnerability of water resources to climate change, integrated water resources management (IWRM) is recognized as a starting point for developing policies that can enhance sustainable water resource management to guarantee water security. They stated that developing water-harvesting and storage infrastructure especially in the drought-prone areas such as Sudano-Sahel could be an approach to improve the adaptive capacity of rural population and increase agricultural output. Some stakeholders at the Ministry of Environment articulated that most adaptation projects at local level fail because of the lack of consultation prior to project conception and execution. They opined that more meaningful consultations with the beneficiary communities are needed to assess weather infrastructural investments envisaged in each locality will reduce their vulnerability to climate change.

This discourse also disagrees with the statement that the media will educate the population on issues related to climate change; instead, the subject should be included in academic programs such as the school curriculum. According to stakeholders, the lack of information for the general public on issues related to climate change can be attributed to the absence of a government policy to disseminate relevant information to the general public. The stakeholders recommended putting in place a national policy to facilitate the dissemination of climate information to the general public.

Discourse $\mathrm{C}$ disagrees with the statement that access to land will increase the adaptive capacity of rural women because they lack basic farm inputs. Most government stakeholders stated that the legal framework in Cameroon gives equal land rights and access to natural resources to both men and women. However, a study in Cameroon showed that the customary tenure system inhibits women from owning land even though they are the main food producers (Nvenakeng 2016). In a related study, Yengoh et al. (2011) reported that reduced agricultural production in Cameroon could be attributed to the scarcity of land for women. Nevertheless, most stakeholders expressed the hope that the new land policy under preparation will take into consideration the possibility for women to own a land in Cameroon. Furthermore, the provision for getting basic farm inputs to farmers was also considered to be another policy direction that could be adopted by the government to boost agricultural output.

Research directions that can strengthen the science-policy interface for climate adaptation were suggested. For example, for integrated water resources management and the construction of water harvest and storage infrastructure in drought-prone zones to be adopted as a government policy; there is a need for sustained research in this area. This research could include pilot studies on the implementation of IWRM at river basin scale so that lessons are learnt before scaling-up at the national level. Other research directions could focus on assessing the impact of water harvest and storage infrastructure and the distribution of farm inputs on the adaptive capacity of the target communities.

\section{Consensus statements}

The PQMethod software also produced a list of consensus statements that did not distinguish between any of the factors and are thus non-significant at $P<0.01$ and $P<0.05$. This implies that there is no significant difference between any of the factor loadings. Of particular interest were statements No 10,24 , and 36 .

Statement 10 is "The tree planting policy under implementation to mitigate the consequences of climate change should be abandoned because it offers no immediate benefits to the local population" (No 10,-3). During post Q-sort interviews, most stakeholders were of the opinion that the tree planting exercise known as "operation green Sahel" in Cameroon is beneficial to the local population because it aims to stop advancement of the desert in the Sudano-Sahel region, prevent and reduce soil degradation in arid and semi-arid areas, and restore degraded lands. Meanwhile, in the long term, it will 
contribute to sequester significant amounts of carbon thus contributing to mitigate global climate change. Statement 24 is "There is sufficient collaboration between the different stakeholders in the area of climate research in Cameroon" (No 24, -2). The majority of stakeholders expressed their frustration during post Q-sort interviews about the lack of collaboration among different institutions working in the area of climate change in Cameroon. This is an indication that at the time this study was conducted, the National Observatory for Climate Change (NOCC) was not yet fully functional. Once operational, it is supposed to serve as collaborative platform that brings different institutions together to promote use of the science-policy interface (SPI) approach to tackle climate change. Statement 36 is "The government is making significant investments in climate science and climate change research and training" (No 36, - 3). Most stakeholders both in government and other organizations were of the opinion that the current investment portfolio of the government in climaterelated research and training was very small which is further compounded by lack of qualified scientist to carry out relevant research for government and private organizations.

\section{Discussion and conclusion}

The objective of this study was to use Q methodology to capture perspectives from multi-level stakeholders holding different viewpoints about climate change. Such information obtained from stakeholders may be useful for strengthening the science-policy interface for climate adaptation in Cameroon. One of the main advantages of using this method is that the capturing and structuring of different viewpoints expressed by stakeholders are done relatively independent of the researcher perspective.

Statistically, the method captured $59 \%$ of the study variance. This high study variance indicates that most of the stakeholders were able to identify with the claims expressed in the three discourses resolved, with each discourse shedding light on a different aspect of climate change in Cameroon. This is one of the strengths of Q methodology because it combines qualitative research techniques to elucidate subjective perspectives, with the statistical robustness of quantitative and repeatable analysis. Rigorous criteria were used to determine the number factors that comprise a discourse, and overall, there was a mean of six participants who scored significantly in each discourse (Table 2), indicating that there was balanced representation on the variety of perspectives. Moreover, the participants with significantly higher scores in each discourse represented different institutions holding different interests on issues surrounding climate change. This is evident by the diverse policy issues proposed by the stakeholders. Making these different voices and opinions visible is an important starting point for building an SPI dialog through a democratic and legitimate process (Few et al. 2007).

The three discourses identified components for strengthening the SPI dialog in Cameroon. Although there was a diversity of stakeholders and diverging views on issues surrounding climate change in Cameroon, the discourses captured opinions on the key thematic areas of vulnerability, impact, mitigation, and adaptation initially retained during filtering of the interview statements to create the Q-sort. The different sectors identified as important for the country's economy and the socio-economic wellbeing of the population, including water resources, agriculture, forestry, and energy, also featured in the three discourses.

It was stated in the "Introduction" section of this paper that for adaptation to succeed, climate science needs to be connected to societal needs, and this could be achieved, at least in part, by creating a science-policy interface. Results from this study have provided new directions on how this can be achieved in Cameroon. For example, adaptation options such as climate services which is the timely production, translation, and delivery of useful climate information and water harvesting were identified by stakeholders as potential adaptation could be used to address issues related to water security in the agricultural sector and urban water supply under different climate scenarios using an interactive approach through co-design and co-production with different stakeholders. Using this approach, adaptation options that address more than one sector at an acceptable cost could be adopted to promote crosssectoral climate adaptation policies in the country. Such evidence-based approach that brings societal needs together with climate science to tackle climate adaptation may go a long way to strengthen the SPI dialog (Watson 2005). Similar approach may be used to enhance cross-sectoral climate adaptation in Cameroon as highlighted by Nkiaka and Lovett (2018) and limit the increasing trend in sectoral initiatives.

Results from this study have also highlighted the practical contribution of the Q methodology in strengthening the SPI dialog to enhance climate adaptation. For example, using this method, it was possible to reveal the sectors and regions that are most vulnerable to climate change impacts in Cameroon and the factors that contribute to exacerbate this vulnerability. Furthermore, different policy interventions that can be put in place to enhance climate adaptation in the country were also highlighted by stakeholders. Therefore, the different policy interventions suggested may be directly applied to address climate impacts beginning with the most vulnerable sectors/regions, and workable and cost effective interventions are scaled-up to address climate impacts in other sectors and regions across the country. Meanwhile, policies aimed at reducing factors that contribute to exacerbate sectoral/regional vulnerability to climate change could also be put in place. 
Given the important role of institutions in enhancing climate adaptation (Conway and Mustelin 2014) and considering that the SPI dialog cannot take place in a vacuum, there is a need for renewed and sustained collaboration between different institutions involved in climate adaptation in Cameroon. This collaboration is needed to enhance and support the SPI dialog given that lack of this collaboration has been highlighted as a significant barrier impeding the mainstreaming of climate adaptation into sectoral policies in Cameroon (Nkiaka and Lovett 2018). However, for this to be successful, institutions charged with managing these sectors must come together to establish a collaborative platform and identify issues of common interests given that they both share similar values in the pursuit of climate adaptation and environmental sustainability. The timely establishment of such a cross-sectoral collaborative platform between different institutions involve in climate change issues is needed to strengthen the SPI dialog in Cameroon.

This article contributes to mitigating against the "streetlight effect in climate change research in Africa" highlighted by Hendrix (2017 p 137). The range of views expressed by the stakeholders interviewed illustrate that research should not just be conducted based on convenience or data availability but should be based on relevance to policy uptake. In contrast to a "top-down" setting of the research agenda by donor agencies and specialist researchers, our study gathers the concerns and hopes of those people who have to make policy on a day to day basis for adaptation and mitigation of the complex impact of climate change.

Overall, results from this study indicated that by using Q methodology, it was possible to identify the most vulnerable sectors/regions to climate change impacts in target country; different approaches of tackling climate adaptation such as multi-sectoral approaches were highlighted; and different policy incentives which can be put in place to facilitate the adaptation process were also identified by the stakeholders without the intervention of the researcher. This indicates that $\mathrm{Q}$ methodology could be a valuable technique for facilitating the science-policy interface dialog for climate adaptation.

Acknowledgments We would like to thank all the stakeholders who took part in this study.

Funding information The authors are indebted to the Commonwealth Scholarship Commission for a scholarship award to the first author and for funding the fieldwork. Writing of this paper was supported in part by GEF grant number GEF-5810 Spatial Planning for Protected Areas under Climate Change (SPARC).

Open Access This article is distributed under the terms of the Creative Commons Attribution 4.0 International License (http:// creativecommons.org/licenses/by/4.0/), which permits unrestricted use, distribution, and reproduction in any medium, provided you give appropriate credit to the original author(s) and the source, provide a link to the Creative Commons license, and indicate if changes were made.
Publisher's Note Springer Nature remains neutral with regard to jurisdictional claims in published maps and institutional affiliations.

\section{References}

Abdi H (2003) Factor rotations in factor analyses. Encyclopedia for research methods for the social sciences. Sage, Thousand Oaks, pp 792-795

Albizua A, Zografos C (2014) A values-based approach to vulnerability and adaptation to climate change. Applying Q methodology in the Ebro Delta, Spain. Environ Policy Gov 24(6):405-422. https://doi. org/10.1002/eet.1658

Alemagi D (2011) Sustainable development in Cameroon's forestry sector: progress, challenges, and strategies for improvement. Afr J Environ Sci Technol 5(2):65-72. https://doi.org/10.5897/ AJEST10.280

André K, Simonsson L, Swartling ÅG, Linnér B-o (2012) Method development for identifying and analysing stakeholders in climate change adaptation processes. J Environ Pol Plan 14(3):243-261. https://doi. org/10.1080/1523908X.2012.702562

Atyi RE a, Assembe-Mvondo S, Lescuyer G, Cerutti P (2013) Impacts of international timber procurement policies on Central Africa's forestry sector: the case of Cameroon. Forest Policy Econ 32:40-48. https://doi.org/10.1016/j.forpol.2012.12.006

Ayonghe SN (2001) A quantitative evaluation of global warning and precipitation in Cameroon from 1930 to 1995 and projections to 2060: effects on the environment and water resources. Reading in Geography:142-155

Ballejos LC, Montagna JM (2008) Method for stakeholder identification in interorganizational environments. Requir Eng 13(4):281-297. https://doi.org/10.1007/s00766-008-0069-1

Barry J, Proops J (1999) Seeking sustainability discourses with Q methodology. Ecol Econ 28(3):337-345. https://doi.org/10.1016/S09218009(98)00053-6

Bele MY, Somorin O, Sonwa DJ, Nkem JN, Locatelli B (2011) Forests and climate change adaptation policies in Cameroon. Mitig Adapt Strat Gl 16(3):369-385. https://doi.org/10.1007/s11027-010-9264-8

Brown HCP, Smit B, Somorin OA, Sonwa DJ, Nkem JN (2014) Climate change and forest communities: prospects for building institutional adaptive capacity in the Congo Basin forests. Ambio 43(6):759 769. https://doi.org/10.1007/s13280-014-0493-z

Brown SR (1980) Political subjectivity: applications of Q methodology in political science. Yale University Press

Byamukama B, Carey C, Cole M, Dyszynski J, Warnest M (2011) National strategy on climate change and low carbon development for Rwanda. Baseline Report

Conway D (2011) Adapting climate research for development in Africa. WIRES Clim Change 2(3):428-450. https://doi.org/10.1002/wcc.115

Conway D, Mustelin J (2014) Strategies for improving adaptation practice in developing countries. Nat Clim Chang 4(5):339-342. https:// doi.org/10.1038/nclimate2199

Crawford A, Hove H, Parry JE (2011) Review of Current and Planned Adaptation Action: Middle Africa. International Institute of Sustainable Development. www.adaptationpartnership.org. Accessed 28 Sep 2016

Cuppen E, Breukers S, Hisschemöller M, Bergsma E (2010) Q methodology to select participants for a stakeholder dialogue on energy options from biomass in the Netherlands. Ecol Econ 69(3):579 591. https://doi.org/10.1016/j.ecolecon.2009.09.005

Davies W, Van Alstine J, Lovett JC (2016) 'Frame conflicts' in natural resource use: exploring framings around Arctic offshore petroleum using Q-methodology. Environ Policy Gov 26(6):482-497. https:// doi.org/10.1002/eet.1729 
Diboma B, Tatietse TT (2013) Power interruption costs to industries in Cameroon. Energ Policy 62:582-592. https://doi.org/10.1016/j. enpol.2013.07.014

Dujardin S, Orban-Ferauge F, Cañares M, Dendoncker N (2017) Capturing multiple social perspectives on adaptation across scales: a Q-method analysis of actors from development planning in the Philippines. Clim Dev 10:1-13. https://doi.org/10.1080/17565529. 2017.1301863

Few R, Brown K, Tompkins EL (2007) Public participation and climate change adaptation: avoiding the illusion of inclusion. Clim policy 7(1):46-59. https://doi.org/10.1080/14693062.2007.9685637

Frantzi S, Carter NT, Lovett JC (2009) Exploring discourses on international environmental regime effectiveness with Q methodology: a case study of the Mediterranean action plan. J Environ Manag 90(1): 177-186. https://doi.org/10.1016/j.jenvman.2007.08.013

Gaston B-W, Tongwa AF, Isabella ZT, Burnley C (2012) Local governance in disaster risk reduction in Cameroon: original research. Jàmbá: Journal of Disaster Risk Studies 4(1):1-9

Hendrix CS (2017) The streetlight effect in climate change research on Africa. Global Environ Chang 43:137-147. https://doi.org/10.1016/ j.gloenvcha.2017.01.009

Howard RJ, Tallontire AM, Stringer LC, Marchant RA (2016) Which "fairness", for whom, and why? An empirical analysis of plural notions of fairness in fairtrade carbon projects, using Q methodology. Environ Sci Pol 56:100-109. https://doi.org/10.1016/j.envsci.2015.11.009

Iyalomhe F, Jensen A, Critto A, Marcomini A (2013) The science-policy Interface for climate change adaptation: the contribution of communities of practice theory. Environ Policy Gov 23(6):368-380. https:// doi.org/10.1002/eet.1619

Jones L, Dougill A, Jones RG, Steynor A, Watkiss P, Kane C et al (2015) Ensuring climate information guides long-term development. Nat Clim Chang 5(9):812-814. https://doi.org/10.1038/nclimate2701

Kline P (2014) An easy guide to factor analysis. Routledge

Koetz T, Farrell KN, Bridgewater P (2012) Building better science-policy interfaces for international environmental governance: assessing potential within the intergovernmental platform for biodiversity and ecosystem services. Int Environ Agreem-P 12(1):1-21. https://doi. org/10.1007/s10784-011-9152-z

Lovett JC (2015) Modelling the effects of climate change in Africa. Afr J Ecol 53(1):1-2. https://doi.org/10.1111/aje.12218

Lovett JC, Nkiaka E (2017) Science-policy interfaces. Afr J Ecol 55(3): 257-258. https://doi.org/10.1111/aje.12456

Lynch AH, Adler CE, Howard NC (2014) Policy diffusion in arid basin water management: a Q method approach in the Murray-Darling basin, Australia. Reg Environ Chang 14(4):1601-1613. https://doi. org/10.1007/s10113-014-0602-3

Molua, E. L. (2007). The economic impact of climate change on agriculture in Cameroon. Policy Research Working Paper; No. 4364. World Bank, Washington, DC

Moss RH, Meehl G, Lemos MC, Smith J, Arnold J, Arnott J et al (2013) Hell and high water: practice-relevant adaptation science. Science 342(6159):696-698. https://doi.org/10.1126/science.1239569

Ndille R, Belle JA (2014) Managing the Limbe floods: considerations for disaster risk reduction in Cameroon. Int J Disast Risk Sc 5(2):147156. https://doi.org/10.1007/s13753-014-0019-0

Nkiaka E, Nawaz NR, Lovett JC (2018) Assessing the reliability and uncertainties of projected changes in precipitation and temperature in CMIP5 models over the Lake Chad basin. Int J Climatol 38: 5136-5152. https://doi.org/10.1002/joc.5717

Nkiaka E, Lovett JC (2018) Mainstreaming climate adaptation into sectoral policies in Central Africa: insights from Cameroon. Environ Sci Pol 89:49-58. https://doi.org/10.1016/j.envsci.2018.07.012

Nkiaka E, Nawaz NR, Lovett JC (2017a) Analysis of rainfall variability in the Logone catchment, Lake Chad basin. Int J Climatol 37(9): 3553-3564. https://doi.org/10.1002/joc.4936
Nkiaka E, Nawaz NR, Lovett JC (2017b) Using standardized indicators to analyse dry/wet conditions and their application for monitoring drought/floods: a study in the Logone catchment, Lake Chad basin. Hydrolog Sci J 62(16):2720-2736. https://doi.org/10.1080/ 02626667.2017 .1409427

Nvenakeng SA (2016) Gender discrimination in customary land tenure systems and its influence on food security and poverty alleviation: lessons from Cameroon. Nature Faune 30(2):32-34

Pavageau C, Locatelli B, Sonwa D, Tiani A-M (2018) What drives the vulnerability of rural communities to climate variability? Consensus and diverging views in the Congo Basin. Clim Dev 10(1):49-60. https://doi.org/10.1080/17565529.2016.1193460

Peach Brown HC (2011) Gender, climate change and REDD+ in the Congo Basin forests of Central Africa. Int Forest Rev 13(2):163176. https://doi.org/10.1505/146554811797406651

Piontek F, Müller C, Pugh TA, Clark DB, Deryng D, Elliott J et al (2014) Multisectoral climate impact hotspots in a warming world. P Natl Acad Sci USA 111(9):3233-3238. https://doi.org/10.1073/pnas. 1222471110

Sarkki S, Niemelä J, Tinch R, van den Hove S, Watt A, Young J (2014) Balancing credibility, relevance and legitimacy: a critical assessment of trade-offs in science-policy interfaces. Sci Publ Policy 41(2):194 206. https://doi.org/10.1093/scipol/sct046

Scoville-Simonds, M. (2016). The governance of climate change adaptation finance - an overview and critique. International Development Policy $\mid$ Revue internationale de politique de développement(7.2). https://doi.org/10.4000/poldev.2243

Somorin OA, Brown HCP, Visseren-Hamakers IJ, Sonwa DJ, Arts B, Nkem J (2012) The Congo Basin forests in a changing climate: policy discourses on adaptation and mitigation (REDD+). Global Environ Chang 22(1):288-298. https://doi.org/10.1016/j. gloenvcha.2011.08.001

Stephenson, W. (1953). The study of behavior: Q-technique and its methodology

Van Exel J, De Graaf G (2005) Q methodology: a sneak preview. Retrieved January 24:2009

Vincent K, Colenbrander W (2018) Developing and applying a five step process for mainstreaming climate change into local development plans: a case study from Zambia. Clim Risk Manag 21:26-38. https://doi.org/10.1016/j.crm.2018.04.005

Water, U. (2009). The United Nations world water development report $3-$ water in a changing world. United Nations Educational Scientific and Cultural Organization, Paris

Watson RT (2005) Turning science into policy: challenges and experiences from the science-policy interface. Philos T R Soc B 360(1454):471-477. https://doi.org/10.1098/rstb.2004.1601

Watts S, Stenner P (2012) Doing Q methodological research: theory, method and interpretation. Sage

Weaver CP, Mooney S, Allen D, Beller-Simms N, Fish T, Grambsch AE et al (2014) From global change science to action with social sciences. Nat Clim Chang 4(8):656-659. https://doi.org/10.1038/nclimate2319

Wilsdon J, Willis R (2004) See-through science: why public engagement needs to move upstream. Demos, London. http://www.demos.co.uk/ publications/paddlingupstre. Accessed 25 June 2017

WRI (2007) EarthTrends: environmental information. World Resources Institute Washington DC

Yengoh GT (2012) Climate and food production: understanding vulnerability from past trends in Africa's Sudan-Sahel. SustainabilityBasel 5(1):52-71. https://doi.org/10.3390/su5010052

Yengoh GT, Hickler T, Tchuinte A (2011) Agro-climatic resources and challenges to food production in Cameroon. Geocarto Int 26(4): 251-273. https://doi.org/10.1080/10106049.2011.556756

Young JC, Jordan A, Searle KR, Butler A, Chapman DS, Simmons P, Watt AD (2013) Does stakeholder involvement really benefit biodiversity conservation? Biol Conserv 158:359-370. https://doi.org/10. 1016/j.biocon.2012.08.018 